


\section{PROPÓSITOS E \\ VALORES: MUITO \\ ALÉM DO LUCRO}

| POR JURACY PARENTE E MARINA HENRIQUES VIOTTO

\section{Condutas mais éticas e transparentes com os clientes, relações com funcionários de mais confiança e objetivos além dos resultados financeiros são três tendências que já começam a fazer a diferença entre os varejistas de sucesso.}

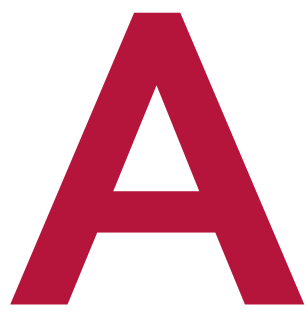

$\mathrm{s}$ intensas alterações causadas pela gradual mudança de valores da sociedade e pela internet já começam a exigir das empresas varejistas uma profunda transformação na filosofia de negócios, na cultura e nos objetivos.

Três grandes tendências devem provocar profundo impacto no varejo nos próximos anos:

- O crescente empoderamento do consumidor, que presta cada vez mais atenção aos valores e propósitos das marcas e, ao mesmo tempo, ganha poder com a rapidez e amplitude com que suas experiências de compra podem ser propagadas na internet;

- As novas exigências de funcionários mais qualificados, que crescentemente vêm da geração milênio (o grupo de jovens nascidos entre 1980 e 2000 que valoriza autonomia e autenticidade);

- A filosofia empresarial denominada Capitalismo Consciente, baseada em valores mais profundos e que começa a ser praticada com sucesso por um grupo de grandes empresas do varejo. Analisaremos a seguir cada uma delas.

\section{EMPODERAMENTO DO CONSUMIDOR}

Nas relações de poder entre varejista e consumidor, verifica-se uma clara mudança a favor deste último. Atualmente, clientes podem propagar e multiplicar suas reações às experiências de compra (de forma positiva ou negativa) rapidamente pelas mídias sociais. Mesmo em empresas bem avaliadas, é significativo o risco de ocorrer alguma situação desfavorável que cause sério dano à reputação. Para minimizar qualquer estrago, o esforço costuma ser enorme.

Consumidores cada vez mais influentes e bem informados passam a exigir que os varejistas adotem condutas mais éticas e transparentes, especialmente a geração denominada de "milênios", que tem entre 18 e 35 anos e valoriza os propósitos das empresas. Algumas tendências de comportamento manifestadas pelos "milênios" merecem destaque. São consumidores que: mostram certa indiferença às marcas caras e aos símbolos de status, são mais receptivos a apelos de produtos que defendem a proteção ambiental (como alimentos e tecidos produzidos com matéria-prima de origem orgânica) e têm mais identificação, confiança e lealdade a marcas de empresas que praticam a boa cidadania e participam de soluções para questões sociais. 
$\mathrm{Na}$ era da internet e dos "milênios", o relacionamento com as empresas ganha um forte vínculo afetivo. Os consumidores indicam não apenas que preferem e gostam da marca, mas que a "adoram". Por exemplo, clientes americanos costumam postar "I love Wegmans" ou "I love Trader Joe 's", indicando que são fãs de alguns dos varejistas mais queridos dos Estados Unidos. Mas a qualquer momento podem, também, postar duras críticas se forem desapontados em suas expectativas.

\section{EMPODERAMENTO DO FUNCIONÁRIO}

Ao pesquisarem antes na internet informações sobre os produtos, os novos consumidores empoderados esperam encontrar nas lojas profissionais que sejam profundos conhecedores do que vendem. Querem esclarecer suas dúvidas e receber conselhos, de forma ética e transparente, sobre a melhor decisão de compra. Nesse contexto, treinamento e incentivo ao processo de contínuo aprendizado dos funcionários tornam-se fatores essenciais para ganho de vantagem competitiva.

A geração milênio, consumidora e mão de obra cada vez mais influente, vem também alavancando o processo de empoderamento dos funcionários. No mercado de trabalho, os "milênios" tendem a: valorizar mais a satisfação no trabalho do que o salário alto; preferir locais onde possam ter mais autonomia; buscar propósito nas tarefas que executam; querer um diálogo franco com as chefias; atuar em empresas que encorajam iniciativa, aprendizado e perspectiva de crescimento profissional.

Ao conversar com gerentes e funcionários nas visitas frequentes que fazemos aos melhores varejistas dos Estados Unidos (como Nordstrom, Lululemon, Ikea, Wegmans, Trader Joe's, Publix e Whole Foods), duas características nos estilos de chefia e gestão, especialmente atraentes às expectativas da geração milênio, têm chamado a nossa atenção: 1) a clareza que os funcionários demonstram sobre os valores e propósitos da empresa, e o entusiasmo que manifestam ao comentarem com orgulho sobre a nobreza dos objetivos da instituição; e 2) a adoção de práticas que estimulam a satisfação e a confiança dos funcionários, tais como: uma definição clara e detalhada de métricas de desempenho; qualificação, horas de treinamento e autonomia do funcionário para atingir suas metas; feedback instantâneo, transmissão frequente dos valores e propósitos da empresa às equipes, uma cultura que incentiva as chefias a serem receptivas e até a estimularem as sugestões dos funcionários, além de reconhecerem e elogiarem o trabalho dos membros da equipe.
Os três supermercados americanos mais bem avaliados pelos clientes - Wegmans, Trader Joe's e Publix - estão também classificados como os três melhores para se trabalhar.

A rede de supermercados Wegmans, a mais bem avaliada nos Estados Unidos pelos clientes, de acordo com uma pesquisa da Consumer Reports, é um modelo em empoderamento dos funcionários. Com mais de 60 mil empregados, a Wegmans dá autonomia a seus profissionais para que garantam a satisfação do cliente e, ao mesmo tempo, cumpram os propósitos da empresa. Os funcionários agem como "donos do negócio". Sentem-se comprometidos para proporcionar um melhor atendimento e estimular um maior engajamento do cliente com a empresa.

No varejo, há intensa relação entre funcionários empoderados e consumidores satisfeitos. Os três supermercados americanos mais bem avaliados pelos clientes - Wegmans, Trader Joe's, e Publix - estão também classificados como os três melhores para se trabalhar pelo ranking da revista Fortune. Com índices de rotatividade de pessoal bem abaixo das médias do setor e salários e benefícios claramente acima dos concorrentes, essas empresas conseguem atender melhor os clientes.

No Brasil, apesar do grande contingente de funcionários da geração milênio, o incentivo ao empoderamento da equipe ainda é limitado. Em conversas com varejistas, verificamos que a rotatividade de pessoal no setor é extremamente elevada, sendo que, em muitos casos, aproxima-se de um assustador índice de $100 \%$ ao ano, bem diferente do índice de $5 \%$ do Wegmans. A situação exige uma profunda mudança de paradigmas, a ser iniciada nos níveis hierárquicos mais altos e disseminada em toda a empresa. Torna-se necessário estimular o desenvolvimento de propósitos empresariais que atendam às expectativas dos "milênios" e promovam mais engajamento dos funcionários; desenvolver sentimento de confiança e mais transparência no ambiente de trabalho e treinar as chefias para aceitarem e estimularem as sugestões e iniciativas dos funcionários, desencorajando os estilos de chefia autoritários. 


\section{CAPITALISMO CONSCIENTE}

Uma nova filosofia de gestão denominada Capitalismo Consciente reflete bem as novas expectativas da sociedade sobre o papel social mais abrangente a ser desenvolvido pelas empresas. Esse movimento vem sendo adotado por um crescente número de empresas varejistas, como Whole Foods, Starbucks, Trader Joe's, Container Store, Nordstrom e Costco. O conceito de Capitalismo Consciente foi sistematizado no livro Conscious Capitalism: liberating the heroic spirit of business, publicado em 2011, escrito por John Mackey, fundador do Whole Foods, e por Raj Sisodia, professor de marketing da Universidade de Babson.

Trata-se de uma filosofia empresarial que busca uma profunda mudança nos paradigmas, nos valores e nas motivações da organização e de todos os seus stakeholders

\section{Os quatro pilares do Capitalismo Consciente}

1. Objetivo superior: propósitos que vão além do lucro, que inspiram e envolvem os demais stakeholders;

2. Orientação para stakeholders: relação ética e transparente em todo o ecossistema de negócios da empresa, a fim de criar e otimizar o valor para todos os públicos com os quais ela se relaciona;

3. Liderança consciente: líderes que visualizam a empresa como parte de um sistema complexo e interdependente e que buscam soluções ganha-ganha baseadas em valores;

4. Cultura consciente: priorização de valores como confiança, autenticidade, consideração, amorosidade, transparência, integridade, aprendizado e empoderamento.

Na National Retail Federation (NRF) de 2017, o principal congresso mundial de varejo que ocorre anualmente em Nova Iorque, as palestras de vários presidentes de empresas varejistas demonstraram a sua adesão aos princípios do Capitalismo Consciente. A fala de Christopher Gavigan, presidente da divisão norte-americana da Ikea - maior rede de móveis do mundo, sediada na Suécia - ressaltou aspectos da empresa que refletem os princípios do Capitalismo Consciente. Segundo a missão e visão da Ikea, a empresa "tem o propósito de criar uma vida cotidiana melhor para a maioria das pessoas. O modelo de negócio sustenta esse propósito ao oferecer uma vasta gama de produtos de mobiliário de casa bem concebidos e funcionais a preços tão baixos que sejam acessíveis à maioria das pessoas". O presidente da Ikea enfatizou princípios e valores, como liderar pelo exemplo, adotar visão de longo prazo, trabalhar com os stakeholders de forma consistente, zelar pelo mundo e manter o compromisso com energias renováveis, cuidar das comunidades em que existem lojas e incentivar o respeito à diversidade no quadro de funcionários.

As ideias do Capitalismo Consciente são reforçadas em outro livro recém-publicado por Raj Sisodia, intitulado Firms of endearment: how world-class companies profit from passion and purpose. $\mathrm{O}$ livro retrata resultados de pesquisas comprovando que as empresas classificadas como as mais conscientes (com base em critérios como: propósitos declarados, remuneração e benefícios aos funcionários, qualidade nos serviços aos clientes e investimento na comunidade e no meio ambiente) vêm apresentando desempenho superior às demais. Por exemplo, as ações de 18 empresas que praticam esses princípios e estão listadas em bolsa de valores nos EUA tiveram um desempenho 10,5 vezes superior do que o índice S\&P 500 (das principais 500 empresas), entre os anos de 1996 e 2011.

Como explica Sisodia em seu livro, a razão para isso é clara: as empresas conscientes tratam seus stakeholders melhor. Como consequência, seus fornecedores estão mais felizes em fazer negócios com elas, seus funcionários são mais engajados, produtivos e estáveis, seus clientes estão mais satisfeitos e leais e suas comunidades acolhem-nas melhor. Ou seja, as empresas mais conscientes dão mais e recebem mais.

\section{CONCLUSÃO}

Clientes e funcionários empoderados e princípios do Capitalismo Consciente vão mudar o cenário do varejo nas próximas décadas. As empresas vencedoras serão aquelas que demonstrarem transparência, mostrarem autêntico compromisso em dar uma contribuição positiva ao mundo e construírem confiança por meio de relações autênticas com todos os stakeholders - ao mesmo tempo em que devem continuar a oferecer, de forma incansável, excelência em produtos e serviços. Será um processo de enorme renovação no "coração" das empresas, que exigirá profundas transformações na escala de valores, nos objetivos de seus dirigentes e na sua deliberada propagação e absorção por todos na empresa.

\footnotetext{
PARA SABER MAIS

Chip Espinoza e Mick Ukleja. Managing the millennials: discover the core competencies for managing today's workforce, 2016.

John Mackey e Rajendra Sisodia. Conscious capitalism: liberating the heroic spirit of business, 2011.

Kip Tindell. Uncontainable: how passion, commitment and conscious capitalism built a business where everyone thrives, 2014

Rajendra Sisodia, David Wolfe e Jagdish Sheth. Firms of endearment: how world-class

companies profit from passion and purpose, 2014

JURACY PARENTE > Professor da FGV EAESP > juracy.parente@fgv.br MARINA HENRIQUES VIOTTO > Aluna de mestrado da FGV EAESP > marina.henriques.viotto@gmail.com 